\title{
Teaching groundwater flow processes: connecting lecture to practical and field classes
}

\author{
V. Hakoun ${ }^{1}$, N. Mazzilli ${ }^{2}$, S. Pistre ${ }^{1}$, and H. Jourde ${ }^{1}$ \\ ${ }^{1}$ Département d'Enseignement des Sciences de la Terre, de l'Eau et de l'Environnement de Montpellier, \\ Hydrosciences Montpellier, UMR5569, CNRS, Université Montpellier 2, 34000 Montpellier, France \\ ${ }^{2}$ Département d'Hydrogéologie, Université d'Avignon et des Pays de Vaucluse, 84000 Avignon, France
}

Correspondence to: V. Hakoun (vivien.hakoun@um2.fr) and H. Jourde (herve.jourde@um2.fr)

Received: 13 December 2012 - Published in Hydrol. Earth Syst. Sci. Discuss.: 24 January 2013

Revised: 17 April 2013 - Accepted: 1 May 2013 - Published: 24 May 2013

\begin{abstract}
Preparing future hydrogeologists to assess local and regional hydrogeological changes and issues related to water supply is a challenging task that creates a need for effective teaching frameworks. The educational literature suggests that hydrogeology courses should consistently integrate lecture class instructions with practical and field classes. However, most teaching examples still separate these three class components. This paper presents an introductory course to groundwater flow processes taught at Université Montpellier 2, France. The adopted pedagogical scheme and the proposed activities are described in details. The key points of the proposed scheme for the course are: (i) iterations into the three class components to address groundwater flow processes topics, (ii) a course that is structured around a main thread (well testing) present in each class component, and (iii) a pedagogical approach that promotes active learning strategies, in particular using original practical classes and field experiments. The experience indicates that the proposed scheme improves the learning process, as compared to a classical, teacher-centered approach.
\end{abstract}

\section{Introduction}

Hydrogeology is essentially an applied science that lies at the boundaries of geology, hydrology, hydraulics, soil sciences, physics and chemistry. Hydrogeology education is directly and indirectly impacted by current environmental challenges. The main challenges associated to groundwater flow processes are the assessment of both local and regional hydrogeological changes and, issues related to water supply.
An effective teaching framework in the hydrogeology field is needed to answer these challenges.

A recent review on pedagogy for hydrogeology education suggests that an effective pedagogical scheme should: (i) integrate the three class components (i.e. lecture, field and practical classes) within an iterative loop in which each would support the others, and (ii) promote learner-centered teaching methods (Gleeson et al., 2012). Noll (2003) exemplifies the shift from a traditional lecture/laboratory format towards an integrated approach. Most educational publications in the area of hydrogeology still dissociate field experiments (such as Woltemade and Blewett, 2002) from laboratory activities (such as Lee, 1998; Singha and Loheide II, 2011; Renshaw et al., 1998). Learner-centered features such as active learning teaching are present in most common inductive instructional methods such as problem-based or project-based methods (Prince and Felder, 2006) and collaborative learning (i.e. group work towards a common goal Millis and Cottell Jr., 1997). The introduction of learnercentered demonstrations, such as small experiments conducted with Darcy bottles or a plexiglass tank, to illustrate concepts associated to groundwater flow into lecture classes is reported to trigger sophisticated questions and discussions. Physical models may help to address quantitative aspects (such as order of magnitude of groundwater fluxes or hydrodynamic parameters) of hydrogeology education (Neupauer and Dennis, 2010; Rodhe, 2012). Numerical models may help to assess and visualize the influence of the parameters involved in hydrogeological processes such as velocity and concentration fields (Singha and Loheide II, 2011) or to address basic modeling concepts such as sensitivity 
analysis (Gates et al., 1996; Li and Liu, 2003). Practical classes with hands-on experiment activities proved to be appropriate to explain physical processes in aquifers (Lee, 1998; Gates et al., 1996; Noll, 2003). Field activities can either be oriented towards passive or active demonstrations and experiments. A strong difficulty encountered in constructing field trips is to adapt the available resources (i.e. site, instruments, etc.) to the student's learning outcomes.

This paper aims to provide an example course on the subtopic of groundwater flow processes, which we define as the motion of water through an aquifer. The key points of the proposed integrated pedagogical scheme are the following: (i) groundwater flow processes topics are addressed iteratively into the three class components (lecture, practical, field), (ii) a main thread is used to support feedback between the three class components, (iii) a pedagogical approach that promotes active learning strategies, in particular using original practical class and field experiments.

This paper is structured as follows. Section 2 sums up groundwater flow processes key topics along to possible learning activities. Section 3 presents an example of structure and material for a course on groundwater flow processes. Section 4 is devoted to the discussion and Sect. 5 to concluding remarks.

\section{Groundwater flow processes for hydrogeologists}

As a consequence of a broader range of background (i.e. diverse earth sciences backgrounds) of students attending a hydrogeology curriculum of advanced studies (Gleeson et al., 2012), it is necessary to provide students with the appropriate basics in groundwater flow processes before subsequent specialty courses are taught. A voluntary survey conducted amongst academic hydrogeologists indicates that the greater part of the crucial topics in a hydrogeology course were related to groundwater flow processes (Gleeson et al., 2012). These topics include for instance: "hydraulic conductivity", "Darcy's law", "gradient and head", "transmissivity".

Based on both the pre-cited survey and our experience, we present in Table 1 a non-exhaustive summary of necessary topics for a course on groundwater flow processes. The different topics are distinguished by the nature of the learning outcome (knowledge or vocational skills) and presented along with both common teacher-centered and learner-centered teaching strategies. Note that the different teaching activities presented in Table 1 are not specific to a single class component. Indeed, active learning teaching strategies cannot be associated with a given category of knowledge (Prince and Felder, 2006). Promoting the involvement of the students in the different class components should improve their commitment to the overall course and thereby improve their learning ability.

Integrated pedagogy is defined by Gleeson et al. (2012) as the combination of the three class components into one single course (Fig. 1). Ideally, learning from the three class components would be combined into a cohesive, iterative whole with mutual feedback from each class component to the others. In this iterative loop, learning advances from one class component to encourage, support and advance learning in the others two class components (Gleeson et al., 2012).

Ideally, the specific teaching goals and learning objectives of each of the three class component would be as follows:

1. lecture classes (associated to exercises) aim to

i. set the course background and review basic notions,

ii. develop the students' knowledge with advanced concepts,

iii. skim over technical field methods,

2. practical classes composed of hands-on experiments aim to

i. develop specific technical and vocational skills,

ii. introduce the learner to critical thinking,

ii. use the theoretical knowledge and concepts learned during lecture classes,

iv. use the data gathered in the field,

3. field work is meant to

i. develop specific vocational skills,

ii. call upon the knowledge and skills learned during lecture and practical classes.

Regarding groundwater flow processes, the theoretical aspects taught in lecture class, when using appropriate activities and material, can effectively be illustrated in practical class or in the field. The students characterize phenomena at different scales (i.e. time and space), in different places (i.e. lecture class, practical class and field) and with different approaches (i.e. theoretical or experimental). As a result, they can sequentially learn, build knowledge bridges, practice and understand groundwater flow processes key topics. Moreover, in an iterative loop between the three kinds of classes, the theoretical concepts learned during lecture classes are supported by triggering the students' curiosity during practical classes and field work.

\section{An adapted teaching loop for a course on groundwater flow processes}

\subsection{Course context}

The course presented hereafter is part of the qualitative and quantitative hydrogeology Master's degree program taught since 2004 at Université Montpellier 2. The course comes during the first spring session (i.e. second semester of the first 
Table 1. Summary table of groundwater flow processes topics associated to teaching strategies.

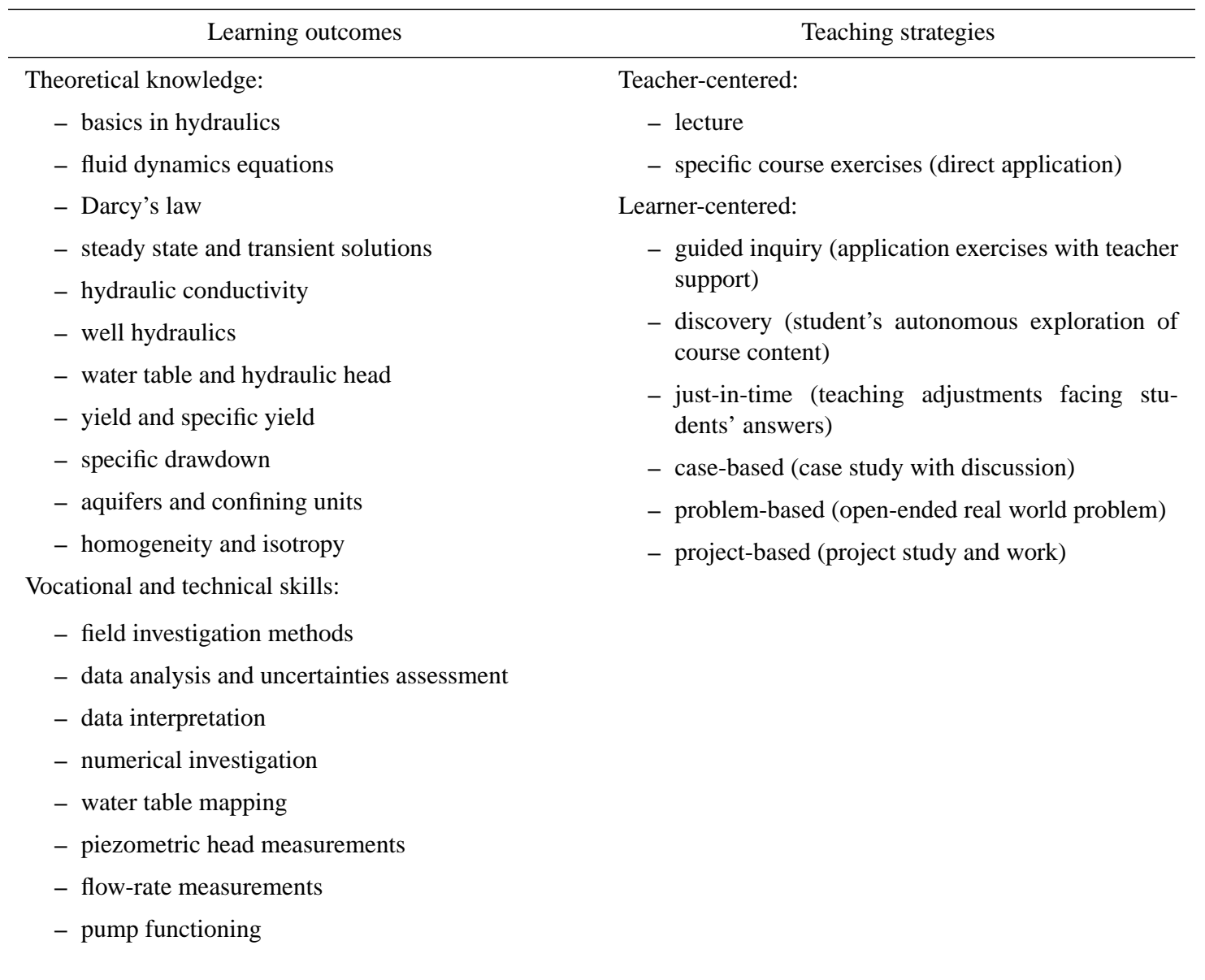

year). It represents 5 ECTS points (European Credit Transfer and accumulation System). Note that a credit point corresponds to $30 \mathrm{~h}$ (student working time) and full-time students take 60 ECTS per year. In this course, the final evaluation test and the practical classes and field reports account respectively for $60 \%$ and $40 \%$ of the global student's mark. The number of students attending this course roughly varies between 20 and 50 depending on the year. The class is divided into small groups (i.e. 10 students) for the practical classes and the field activities. The students who follow this introductory course to groundwater flow processes come from both the geosciences curriculum taught at Université Montpellier 2 and other universities or schools.

\subsection{Learning goals and overall teaching approach}

The learning goals of this course are:

- general knowledge of aquifers types and properties,

- fundamental laws and equations to describe groundwater flow processes,
- analytical and numerical models as a tool to solve groundwater flow problems and assess hydrodynamic parameters,

- quantitative analysis of groundwater problems,

- numerical modeling of groundwater flow and transport.

The students are expected to have at least a basic knowledge in hydrogeology (Darcy's law, porosity, etc.) general geology, mathematics and physics, even though small knowledge discrepancies are generally observed in particular in between students coming from distinct universities.

The overall teaching approach promotes active participation during the different classes either through open topic questions, exercises, or experiments in order to favor the students' knowledge construction and student-teacher discussions. As an example, during lecture class, short time windows are dedicated to interactively solve exercises with inputs from the students. The applied field case motivates the students through its professional aspect.

For this course devoted to groundwater flow processes, the ideal integrated pedagogy presented in Sect. 2 and illustrated 


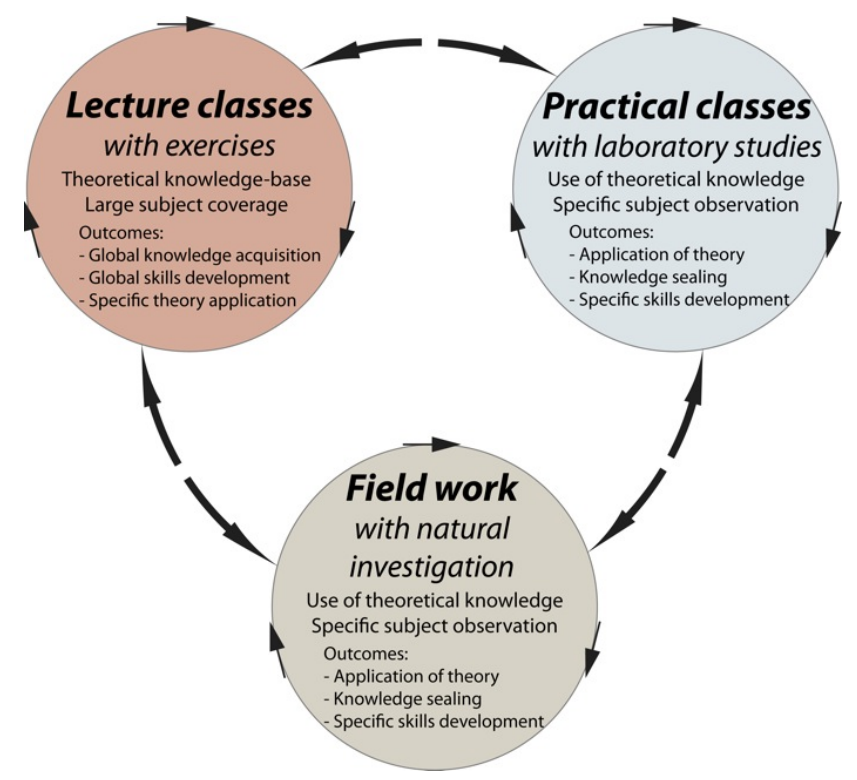

Fig. 1. Our interpretation of an integrated hydrogeology pedagogy associated to an iterative loop over three class components. Within an iterative loop, each component support the others with mutual feedback. Inspired from Gleeson et al. (2012).

in Fig. 1 is adapted in order to fit the university's time and material constraints. Figure 2 illustrates the adapted version of the ideal integrated pedagogy. First, within an iterative loop between lecture class and practical class, essential basics and methodology of groundwater flow processes are taught and practiced. At the end of the course, applied-casebased fieldwork recalls most of the topics covered during the course. This adapted integrated pedagogy allows, for each class component, to attain most teaching goals (Sect. 2), with the exception of the use in practical class of data gathered in the field.

Groundwater scarcity and quality issues are stressed (repeatedly) in the pedagogical activities. During practical classes, the discussion is fostered by the experiment design, which is meant to minimize the amount of waste water. The local context also offers an opportunity to address aquifer recharge and groundwater scarcity issues: the city of Montpellier is located in a region under the influence of Mediterranean climate, and drinking water supply depends entirely on groundwater.

Students are recursively reminded of the specific topic of groundwater flow processes during the course. Using a main thread is meant to ease the transition between the different topics tackled during the course, and to maintain the student's interest at a high level. The requirements for the selected topic are: (i) to cover a large range of theoretical concepts and vocational skills, (ii) to fit in lecture, practical and field classes, and (iii) to answer the student need for professional skills. For this course, well testing was selected as the main thread based on the following considerations: (i) it is a key

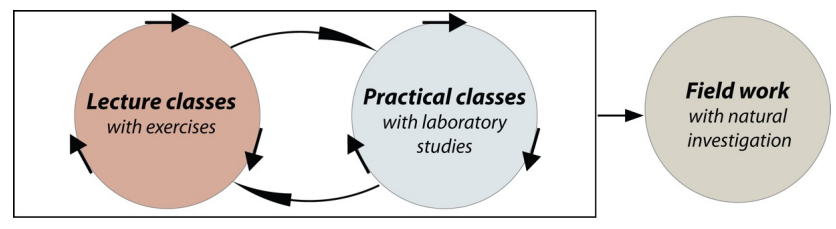

Fig. 2. The adapted iterative loop structure over the three class components for an integrated pedagogy for the presented course devoted to groundwater flow processes. At first, the students progress within a cycle between lecture class and practical class. Once this cycle ends, the students are taken in the field and investigate an applied case.

topic in groundwater flow processes with various complexity levels, (ii) it is the meeting point between theory and field investigations, and (iii) it is an essential/prerequisite tool for any hydrogeologist engineer or scientist.

\subsection{Lecture class}

The lecture class is where the basis of groundwater flow processes are taught and is the starting point of the iterative loop presented in Fig. 2. The theoretical aspects tackled in the course are illustrated by short application exercises where the teacher can deploy the different learner-centered teaching methods presented in Sect. 2. The success here depends strongly on the student dynamics (i.e. number of students, reaction) in class. A classical overall assessment is conducted at the end of the semester, with exercises similar to the ones seen in lecture class.

\subsection{Practical classes}

The practical class adopts an experiential learning context, based on three original hands-on experiments that we especially designed for educational purposes. The two physical models presented hereafter work in a closed system of water, avoiding a waste of water. A group report (in a scientific format) has to be written by the students and is due by 15 days after the end of the course. For this report, the assessment criteria emphasize the students' interpretations and discussions.

The first hands-on experiment (circular tank) is meant to address the following groundwater flow processes topics: (i) the effect of a well pumping at a constant rate on the shape of the water table (head fields) in steady-state conditions and its change over time in transient conditions, (ii) the analysis of steady-state data with analytical solutions (such as the Dupuit-Thiem's solution) to assess the hydrodynamics parameters of the aquifer analogue, (iii) the validity of using Theis' solution with transient-state data in an unconfined aquifer to assess the hydrodynamics parameters of the aquifer analogue and, (iv) the use of the superposition principle to interpret the head field between two pumping wells. Figure 3 (top) presents the associated apparatus. Details of 
both the material and the proposed activities are provided in Appendix A.

The second experiment (rectangular tank) addresses the following topics: (i) the use of Darcy's law in unconfined conditions, (ii) the definition of a protection perimeter around a pumping well on the basis of the head and velocity fields measured on the aquifer analogue and, (iii) the pumping well's maximum flow rate. Figure 3 (middle) presents the associated apparatus. Details of both the material and the proposed activities are provided in Appendix B.

The third experiment (numerical model) is closely related to the previous experiment (i.e. rectangular tank): when effectively conceptualized, similar results are obtained. This experiment is meant to address the following topics: (i) the effect of confined and unconfined aquifer settings on the water table shape, (ii) the influence of heterogeneous permeability fields on flow processes through porous media, (iii) the influence of the boundary conditions on the well productivity. Unlike physical experiments, numerical simulations have the attracting feature of fast flexibility and allow for the exploration of the influence of both varying boundary conditions and aquifer settings. The results of the simulations are interpreted and compared with reference to those obtained with the second experiment (i.e. rectangular tank). Details of both the material and the proposed activities are provided in Appendix $\mathrm{C}$.

The implementation of the iterative loop between lecture class teaching and practical activities (Fig. 2) can be exemplified as follows:

1. Lecture class: introduction to groundwater flow topics related to aquifer settings and hydraulic properties. Aquifer types and settings are exemplified by porous, fractured, karstified and confined or unconfined aquifer examples. Boundary conditions and common flow equations such as Darcy's law can also be presented. Application exercises involve for instance gradient, flow calculations, drawing and analysis of equipotentials with if needed - teacher supervision.

2. Practical class: the different activities begin by carrying simple flow experiments in relation with the lecture class topics. The introduction of more complex experiments (such as complex calculations) triggers the student's motivation to learn and explore new concepts. Taking the example of the rectangular tank apparatus, students set up the experiment (constant pressure boundaries) and measure local pressure heads and outflow. Groundwater flow processes are interpreted based on equipotential and velocity field maps built from measured data. Outflow is calculated assuming an equivalent homogeneous hydraulic conductivity.

3. Lecture class: the lecture focuses on topics related to flow towards a pumping well, such as well test analysis methods and the associated analytical solutions. The

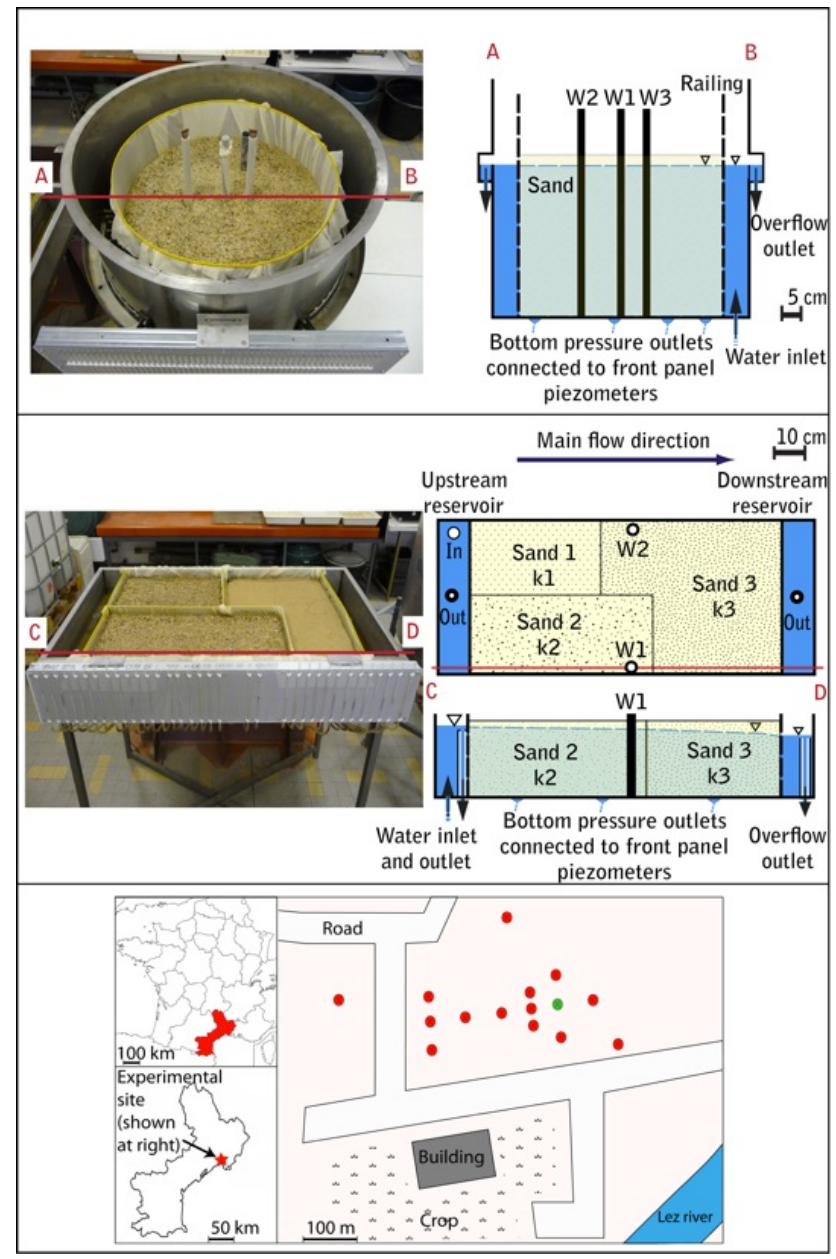

Fig. 3. Photographs and schematics of the circular (top) and rectangular (middle) tanks, schematic plan of the experimental well test site (bottom). Circular tank schematic (top right): cross section along the $\mathrm{AB}$ profile, $\mathrm{W} 1, \mathrm{~W} 2$ and $\mathrm{W} 3$ stand for the wells. Rectangular tank schematics (middle right): plan view and cross section along the DC profile, $\mathrm{k} 1, \mathrm{k} 2$ and $\mathrm{k} 3$ (here $\mathrm{k} 1>\mathrm{k} 2>\mathrm{k} 3$ ) are the respective hydraulic conductivities of sand areas 1, 2 and 3, W1 and W2 are wells. Experimental well test site (bottom): the red dots stand for the piezometers, the green dot stands for the pumping well.

exercises focus on well test interpretation solutions and wells' protection area assessment.

4. Practical class: with the circular tank aquifer analog, students will set and perform various pumping and injecting tests during the practical class. Experimental results are interpreted with use of the theory and methodology seen in the classroom.

\subsection{Field class}

The field class takes place in a well field facility that was initially designed for research purpose (see general settings in Fig. 3 bottom). The field experiment has a low impact on 
the groundwater resource as it is strongly influenced by the near flowing river (see details in Appendix C).

The aim of the field class is to: (i) assess the local hydraulic and chemical aquifer properties, (ii) characterize and interpret the local groundwater flow processes, (iii) identify the uncertainties related to the field methods.

A professional form report has to be written by the students and is due by 15 days after the end of the course. The evaluation of this report focuses on the discussions related to the results and the students' interpretations of the pumping test. The activities conducted on the field can be divided into three steps. The supervision consists in refining the students objectives, roles and tasks to address effectively the field work. This management is meant to avoid time loss.

1. Data collection for the pre-pumping characterization of the local groundwater flow processes. This characterization includes:

i. pre-perturbation measurements of the piezometric heads in each observation well,

ii. deploying data-loggers with help of a field technician,

ii. borehole characterizations by means of depth/temperature and electrical conductivity logging,

iv. setting the pumping line in the pumping well.

2. Transient-state data collection during the drawdown phase of the pumping test. The pump is started by the technical team. During the transient phase of the pumping test, the students perform the following:

i. manual piezometric heads measurements in observation wells (by groups of two),

ii. flow measurements at the outlet of the pumping line,

iii. borehole $\operatorname{logs}$ with temperature and electric conductivity sensors.

3. Transient-state data collection during the recovery of the pumping test. The technical team stops the pump when a steady state (or pseudo-steady state) is reached. The students continue their manual piezometric heads measurements until the end of the buildup phase.

\section{Discussion}

The proposed course has been taught since 2004. The current pedagogical scheme is the result of a gradual evolution over the 2004-2012 period. During this time span, practical classes have been supplemented with (i) the rectangular box with numerical modeling activities and, (ii) the circular tank experiment. The key points of the adopted pedagogical scheme are: (i) an integrated pedagogy with an adapted iterative loop between the three class components (Fig. 2), (ii) the articulation of the course around a main thread in each class component, and (iii) the promotion of active learning strategies, and particularly through the development of original practical classes and field experiments.

Each year an evaluation of the Master's program is conducted by means of feedback questionnaires and positive feedback were received from the students. Most student feedback stressed that both lab-experiments and field experiments greatly improved their understanding of groundwater flow processes, thanks to the link it provided between theory and practice. The students' behavior (i.e. classroom discussions and exam results) also confirms the positive impact of the pedagogical scheme. Individual student results at the final assessment were strongly correlated to the results of practical classes group reports, which evidences the efficiency of collaborative learning for groundwater flow processes teaching. At first, group work acts as an ice breaker and helps the integration of students from other universities. Then, it supports direct help between the students. Writing group reports also develops students' team management skills. Finally, the sustainable teaching materials increase the student's awareness on critical groundwater issues such as water scarcity or pollution. These elements suggest that the proposed pedagogical scheme has a positive impact on student learning outcomes, as compared to a teacher-centered scheme. It also favors discussions between the students and the teachers and potentially whets the appetite for academic research.

Possible improvements to the proposed course are related to (i) improvements in the proposed pedagogical scheme and (ii) improvements in the practical classes' apparatus.

Regarding the pedagogical scheme, we note the following:

- improvements of the feedback regarding student assignments. Formative assignments help the students' learning throughout the course by the feedback the teacher provides on their work. Combining online feedback systems and electronic work submission help the student get written feedback (Hatziapostolou and Paraskakis, 2010; Hartford, 2007). Implementing formative assignments in the actual course may be achieved for instance, by dividing practical or field group reports into formative and summative parts.

- improvement of individual contribution assessment in group assignments. Assessing individual contributions through group assignments is a delicate process (Johnston and Miles, 2004). The identification of individual contribution in group assignments may be improved for instance by (i) introducing identified tasks that should be addressed individually and (ii) combining group average and individual marks.

- improvement in the mutual feedback between the three class components, for instance by implementing a 
practical class activity for the interpretation of fieldgathered data. Note that as interpretation methods are already applied in lecture classes exercises, this activity could be rapidly implemented and thus fit the time schedule constraint.

- enhancement of student participation in lecture classes, for instance by showing videos (Gleeson et al., 2012) or introducing analogue aquifer/process models with simple demonstrations (Neupauer and Dennis, 2010; Rodhe, 2012).

Possible improvements in the practical classes' apparatus (experiment 1 and 2) and activities include (i) adding a colorant to the liquid in the piezometer tubes in order to ease the water level reading and thus increase the time for data analysis and process interpretation, and (ii) designing a data logger with a sampling frequency and accuracy adapted to the fast processes of the physical model. The addition of new activities to the practical classes, using the existing apparatus can also be considered; for example, activities related to diffuse recharge and mass transport could easily be added to experiment 3 (numerical model).

\section{Conclusions}

The challenges in teaching groundwater flow processes are principally related to the multidisciplinary aspects of the topics taught and the diversity of the students' backgrounds, motivations and professional goals (for instance, research or industry). In this context, an effective teaching framework has to promote learner-centered activities, whenever possible (Gleeson et al., 2012). In this paper, we presented a brief summary of the different key topics that should be addressed in a course dealing with the basics of groundwater flow processes, along with a detailed pedagogical scheme to address a course on the basics of groundwater flow processes. The example course provided herein illustrates the current shift of educational methods (i.e. from teacher-centered to learnercentered). The integrated pedagogical scheme associated to this course associates the three class components (lecture, practical and field classes).

The key points of the adopted integrated pedagogical scheme are (i) groundwater flow processes topics that are addressed iteratively into the three class components, (ii) a main thread that is used to support feedback between the three class components, and (iii) a pedagogical approach that promotes active learning strategies, in particular using original practical classes and field experiments. The iterative loop set in between lecture and practical classes allows for the association of theoretical and applied topics in student-centered learning activities and leads the course toward an applied field case. Throughout the course, the learner's interest is stimulated with the recursive topic of well testing in each class component. The large range of topics related to well testing allows the teacher to cover increasingly complex notions.

Our experience indicates that this pedagogical scheme improves not only the learners' motivation but also their peer relation and learning ability as compared to more conventional teacher-centered lecture. The experiments conducted in practical classes and in the field help increase the students awareness of groundwater scarcity issues. The introduction of new experiments dedicated to practical classes proved possible at a reduced cost. In the same way, developing new field activities needed only an access to a pumping field for a day. These new experiments could therefore be included in an adapted form to groundwater flow processes courses in developing countries in which groundwater issues are crucial.

\section{Appendix A}

\section{Circular tank apparatus}

\section{A1 Material}

A photograph and a schematic representation of this physical model are presented in Fig. 3 (top). The circular tank $(H \times r=100 \times 50 \mathrm{~cm})$ is made from stainless steel with waterproof joints. Stainless steel was chosen to avoid premature corrosion. Before assembling, we recommended that the builder drill and cut all the necessary holes on (i) the future bottom face (i.e. inflow, wells, pressure probes and inner circular railing fixation) and, (ii) the outer face (i.e. overflow exits). An inner circular railing with a radius of $35 \mathrm{~cm}$ and a large mesh is filled with a homogeneous, medium-sized sand (hydraulic conductivity $\approx 10^{-5} \mathrm{~m} \mathrm{~s}^{-1}$ ) over a height of about $50 \mathrm{~cm}$. Three screened PVC pipes (diameter $=2.5 \mathrm{~cm}$ ) screwed to the bottom of the tank integrally cross the sand layer. Each well is controlled by an individual faucet under the tank. Water inflow to the physical model is ensured with constant water level condition. The water is pumped from an independent water tank. Inflow occurs at the bottom of the circular tank in the free space between the inner railing and the outer tank. Three overflow outlets located at an equal distance from each other and at an identical height on the outer side allow for a homogeneous constant head in the tank $(h=45 \mathrm{~cm})$ around the sand layer. Water flowing through the overflow outlets returns to the independent water tank. Outer flows from the wells or the overflow outlets are measured with the help of a graduated cylinder and a chronograph. Water levels in the sand are monitored by a network of 52 small holes (diameter $=0.7 \mathrm{~cm}$ ) drilled at the tank's bottom. Flexible transparent PVC pipes link each hole to vertical transparent glass tubes (diameter $=0.7 \mathrm{~cm}$ ) placed on a board in front of the tank. These tubes serve as monitoring "piezometers". Note that this pressure observation system is sensitive to trapped air bubbles. Transparent pipes ease the tracking of potentially trapped bubbles. We also advise respecting the 
indicated diameter to avoid capillarity effect in the vertical tubes. An actual piezometer is built out of a screened pipe (diameter $=2.5 \mathrm{~cm}$ ) and placed in the sand between a well and the outer railing. It provides an access to the water table level (i.e. head) from the top of the physical model and can host a data logger sensor. To minimize sand spreading outside the inner railing, inside the wells or the pressure holes, we recommend placing a thin net around the wells, on the inner side of the railing and on the bottom of the tank. Of course the net should have a mesh aperture lower than the grain size. Synthetic net curtain bought by the meter perfectly fit the need. We encourage the interested reader to contact the authors for further information on the construction of the physical model.

For this apparatus, the most important part of the cost is due to the stainless steel tank construction. The total cost depends on the facilities offered to the teachers aiming at constructing such lab experiments and may vary approximatively between $500 €$ (furniture only) up to $5000 €$ (lab experiment completed by an external company). These indicative prices neither include the injecting pump nor the data logger sensor (approximatively $1000 €$ ). Potential savings can be realized by self-assembling the experiment components (i.e. railing, pipes, piezometer board) and using another building material, for instance Polymethyl Methacrylate (PMMA).

\section{A2 Activities}

During practical class, the circular tank apparatus is used to mimic the following configurations: (i) one well producing at a constant rate in a porous aquifer bounded by a constant head boundary, (ii) two wells producing at a constant rate in a porous aquifer bounded by a constant head boundary, and (iii) one injecting well close to a pumping well, both with the same injecting and pumping rate.

The tasks of observation, description and measurement of the flow at the wells and of the water levels in the sand in steady and transient state allows students to explore groundwater flow processes theory. The theoretical quantitative aspects of groundwater flow processes are put in practice by using for instance the Dupuit-Thiem approximation to interpret steady-state measurements and derive the hydraulic conductivity of the well's surrounding sand.

Transient-state data are gathered by the pressure sensor placed in the piezometer. The results of the steady state and transient state characterizations of the sand medium are discussed and compared in the group report. The validity of the superposition theorem in unconfined aquifer conditions is also discussed based on the gathered data. Given the proposed activities, it is very apparent that for relatively small drawdowns (as compared to the aquifer thickness), the errors induced by the use of pumping test interpretation methods developed for confined flow conditions or by the use of the superposition theorem may be deemed negligible.

\section{Appendix B}

\section{Rectangular tank apparatus}

\section{B1 Material}

A photograph and a schematic representation of this physical model are presented in Fig. 3 (middle). The apparatus is a rectangular stainless steel sand box $(l \times L \times h=120 \times 90 \times 20 \mathrm{~cm})$ (Fig. 3 middle). It is divided into five compartments by means of internal railing. Two compartments are saved for the upstream and downstream reservoirs. The three compartments left are filled with distinct uniform grain-sized sands (hydraulic conductivities $k_{1} \approx 10^{-3} \mathrm{~m} \mathrm{~s}^{-1}, k_{2} \approx 10^{-4} \mathrm{~m} \mathrm{~s}^{-1}, k_{3} \approx 10^{-5} \mathrm{~m} \mathrm{~s}^{-1}$ ). In order to avoid sand spreading and mixing, a thin synthetic net is placed on the railing walls (the same technique is used for the circular tank apparatus, see Appendix A1). Water is flowing in a closed loop from a reserve water tank to the rectangular tank. A permanent inflow is maintained to the upstream reservoir and constant head conditions in both upstream and downstream reservoirs are obtained using overflow outlets. Water flowing out from the tank returns to the reserve water tank. Further information on the construction of the physical model may be asked to the authors.

The gradient between the upstream and the downstream reservoirs can be changed by adjusting the height of the overflow outlets. Steady state is reached within a few minutes. At mid length, the rectangular tank is drilled to receive two screened pipes (made from $1 \mathrm{~cm}$ diameter pipes of plumbing) screwed to the bottom face of the tank. These pipes are meant to stand for fully penetrating wells in the aquifer model and can be activated by opening a faucet located under the tank. Pressure heads are monitored at 34 locations using the methodology detailed in Appendix A1. Pressure measurements are in particular performed in both wells and in both upstream and downstream reservoirs. Monitoring piezometers are placed on the tank's face, similarly to the circular tank apparatus. Flow measurements are performed manually at the wells outlets and at the outlet of the tank apparatus, using a graduated cylinder and a chronograph. The costs of this apparatus are similar to that of the circular tank (from $500 €$ up to $5000 €$, see costs remarks in Appendix A1). Potential costs reductions can be achieved by using PMMA for the tank construction.

\section{B2 Activities}

With this physical model, the students are introduced to the influence of heterogeneities in the hydraulic conductivity on the groundwater flow processes, in steady state conditions. Water table level and flow rate measurements are performed at the different outlets for different flow configurations as with (i) regular flow through the sand layers (no producing well), (ii) one producing well, and (iii) two producing wells. 
With the help of water table maps, cross-sectional views and water budgets the students practiced performing: (i) an approximate outflow determination with use of an equivalent homogenous aquifer solution and Darcy's law, (ii) the determination of a potential protection perimeter around a pumping well, (iii) the maximal flow rate determination for the pumping well.

\section{Appendix C}

\section{Numerical model}

\section{C1 Material}

Up to year 2012 the introduction of numerical simulation to the students was performed using the free educational software Aquifer Simulation Model for WINdows (ASMWIN) developed by Chiang et al. (1998). Since the newest versions of MS-Windows ${ }^{\mathrm{TM}}$ does not support ASMWIN anymore, another free software Processing Modflow for Windows (PMWIN) developed by Chiang and Kinzelbach (2001) is used. An executable file can be downloaded online at the following address: http://www.pmwin.net/. This model runs on most MS-Windows ${ }^{\mathrm{TM}}$ operating systems. PMWIN is a program which brings the various code related to MODFLOW together. MODFLOW is the 3-D finite difference groundwater flow model developed by the US Geological Survey. Note that among the different programs developed along to MODFLOW exist PMPATH (advective transport and particle tracking code by Chiang and Kinzelbach, 1994). PMWIN also includes a graphical user interface which facilitate pre- and post-processing for MODFLOW, thus making its use fairly straightforward. The results of the simulations can be exported in different file formats for later representation and interpretation with other numerical tools.

\section{C2 Activities}

First, the students set a numerical model of a homogenous aquifer with (i) dimensions similar to those of the rectangular box described in Appendix B and, (ii) the previously found equivalent average hydraulic conductivity value. The students can check the consistency between numerical results and the measured hydraulic head in the sand tank. Additional simulations are run for configurations of increasing complexity, including (i) confined and unconfined equivalent homogeneous aquifer, (ii) confined and unconfined heterogeneous aquifer, (iii) confined and unconfined heterogenous aquifer with a pumping well. That later configuration introduces the particle tracking. In the final group report, the results of the simulations have to be presented in a particular form (piezometric contour lines with a defined interval and water budgets), which ask the students to explore the software's functionalities.
The proposed activities aim to develop conceptualization skills. For example, setting up a numerical model of the rectangular sand box addresses the issue of acceptable boundary conditions. Note that these conceptualization skills and problem solving techniques can then be used in fields broader than the groundwater flow processes topic.

\section{Appendix D}

\section{Field class}

\section{D1 Geological setting and material}

A schematic plan representation of this well test site is presented in Fig. 3 (bottom). The well site is located nearby the university campus (accessible in less than $20 \mathrm{~min}$ ). The field facility is relatively protected against malicious acts. The site is in an enclosed area and the head of the well and the piezometers are locked after each experiment. Most of the costs of this activity are related to wells drilling. Note that the drilling costs may vary depending on the number of wells and the geological context. A solution with numerous wells is preferable because it provides the opportunity to (i) split the group of students for monitoring activities and, (ii) explore the hydraulic properties of the aquifer in a broader way. However these points also depend on the number of students. We recommend targeting aquifers with simple hydrogeological contexts such as alluvial aquifers in relation to a perennial river. This solution avoids deep drilling, it allows the experiment to be conducted any time of the year with deem impact on the groundwater resource.

The geological context is constituted of Quaternary alluvial deposits and marine Neogene deposits. The local stratigraphy can be described as an alternation of sedimentary layers of sand, clays and gravels over a depth of about $30 \mathrm{~m}$. These stratified sediments lie over a thick layer of Miocene marls. The site has two aquifers horizons: the upper, unconfined aquifer horizon located within the top layers' alternation of sand and clays and the lower confined or semiconfined aquifer horizon located within the deeper gravel layer. The marly level is the bedrock of the gravel aquifer. The well field facility comprises a total of 15 boreholes (Fig. 3 bottom) over an area of approximatively $5000 \mathrm{~m}^{2}$. The boreholes are integrally screened with plastic pipe and they all reach the aquitard at their bottom. Piezometric measurements indicate that both aquifers may be either drained or fed by the close flowing Lez river depending on the season. When conducting pumping tests, the pumped water can be expelled to the river through the city's rainwater network pipe.

\section{D2 Activities}

The proposed activities aim to investigate the local groundwater flow processes behavior. The field class starts with a 
quick review of the geological context of the site, of the sequence of activities and of the investigation methodology (ideally, this teacher's intervention would be avoided). Thereafter, data collection can be divided into three steps. First, the students set and dispatch pressure probes (data loggers) in the observation wells with the help of the technical team. Manual water level measurements are performed in each well for later characterization of the pre-pumping hydrodynamics. Conductivity and temperature borehole logs are conducted with a data logger in selected wells. For technical reasons, the pump is already set in the pumping well before the students get on site but the pumping equipment is described by the group. Then, the pump is started by the technician team. The transient aquifer's response to the pumping is manually monitored by the students (by groups of two) and by the dispatched data loggers. The manual measurement frequency is adequately set to the drawdown rate of change. Conductivity and temperature logs can be conducted parallel to water level measurements once the manual measurement frequency is low. Flow rate measurements are performed throughout the pumping test using a $3 \times 10^{-1} \mathrm{~m}^{3}$ plastic tank and a chronograph at the outlet of the pumping line. Last, the pump is stopped and the recovery phase is monitored manually. The students are asked to produce an interpretation report about the local hydraulic properties of the aquifer, based on the gathered data. The field results indicate that at early times the well produces the gravel horizon. At late times, recorded data shows a drainage effect, which is interpreted as a contribution from the upper unconfined aquifer (sand and clays). Early data interpretation with the students may be conducted in the field which call upon the concepts seen theoretically in lecture class.

Acknowledgements. The authors thank V. Leonardi at the Département d'Enseignement des Sciences de la Terre, de l'Eau et de l'Environnement de Montpellier (DESTEEM) for interesting discussions on this manuscript. They also thank F. Perdieu at the DESTEEM for its help in the construction of the practical classes equipment, and F. Hernandez and E. Gayrard (Hydrosciences Montpellier Laboratory), for their valuable help with the field activities. This material was supported by the Faculté des Sciences. The authors also thank the Editor, Tom Gleeson and an anonymous reviewer for their careful reading of the manuscript and valuable suggestions.

Edited by: J. Seibert

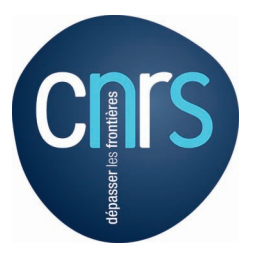

The publication of this article is financed by CNRS-INSU.

\section{References}

Chiang, W. and Kinzelbach, W.: PMPATH, An advective transport model for Processing Modflow and Modflow, Geological Survey of Hamburg, Germany, 1994.

Chiang, W. and Kinzelbach, W.: 3D-groundwater modeling with PMWIN, Springer, 2001.

Chiang, W., Kinzelbach, W., and Rausch, R.: Aquifer simulation model for Windows: groundwater flow and transport modeling, an integrated program, Bornträger, 1998.

Gates, A., Langford, R., Hodgson, R., and Driscoll, J.: Groundwater simulation apparatus for introductory and advanced courses in environmental geology, J. Geosci. Educ., 44, 559-564, 1996.

Gleeson, T., Allen, D. M., and Ferguson, G.: Teaching hydrogeology: a review of current practice, Hydrol. Earth Syst. Sci., 16, 2159-2168, doi:10.5194/hess-16-2159-2012, 2012.

Hartford, T.: Computer based feedback: friend or foe?, Assessment, Teaching and Learning Journal (LeedsMet), 2007.

Hatziapostolou, T. and Paraskakis, I.: Enhancing the impact of formative feedback on student learning through an online feedback system, Electronic Journal of e-Learning, 8, 111-122, 2010.

Johnston, L. and Miles, L.: Assessing contributions to group assignments, Assessment \& Evaluation in Higher Education, 29, 751-768, 2004.

Lee, M.: Hands-on laboratory exercises for an undergraduate hydrogeology course, J. Geosci. Educ., 46, 433-438, 1998.

$\mathrm{Li}, \mathrm{S}$. and Liu, Q.: Interactive groundwater (IGW): An innovative digital laboratory for groundwater education and research, Comp. Appl. Eng. Educ., 11, 179-202, 2003.

Millis, B. and Cottell Jr., P.: Cooperative learning for higher education faculty, Series on higher education, American Council on Education, ORYX Press series on higher education, 1997.

Neupauer, R. and Dennis, N.: Classroom activities to illustrate concepts of Darcy's law and hydraulic conductivity, J. Prof. Iss. Eng. Ed. Pr., 136, 17-23, doi:10.1061/(ASCE)10523928(2010)136:1(17), 2010.

Noll, M.: Building bridges between field and laboratory studies in an undergraduate groundwater course, J. Geosci. Educ., 51, 231236, 2003.

Prince, M. and Felder, R.: Inductive teaching and learning methods: Definitions, comparisons, and research bases, J. Eng. Educ., 95, 123-138, doi:10.1002/j.2168-9830.2006.tb00884.x, 2006.

Renshaw, C., Taylor, H., and Reynolds, C.: Impact of computerassisted instruction in hydrogeology on critical-thinking skills, J. Geosci. Educ., 46, 274-279, 1998.

Rodhe, A.: Physical models for classroom teaching in hydrology, Hydrol. Earth Syst. Sci., 16, 3075-3082, doi:10.5194/hess-163075-2012, 2012.

Singha, K. and Loheide II, S. P.: Linking Physical and Numerical Modelling in Hydrogeology using Sand Tank Experiments and COMSOL Multiphysics, Int. J. Sci. Educ., 33, 547-571, 2011.

Woltemade, C. and Blewett, W.: Design, implementation, and assessment of an undergraduate interdisciplinary watershed research laboratory, J. Geosci. Educ., 50, 372-379, 2002. 